\title{
O MUNDO CIVILIZADO NO SÉC. VI: A OPOGRAFIA CRISTÃ DE COSME INDICOPLEUSTES.
}

\author{
Walter Oliveira Lossio Jr. ${ }^{1}$
}

RESUMO: Os contatos entre Ocidente e Oriente costumam figurar como tópicos dignos de atenção apenas após o advento da Idade Média. No entanto, é recorrente a conclusão de que ambas as partes já possuíam, ao menos, conhecimento do "outro lado" em períodos muito anteriores e de que o fluxo de trocas culturais, sociais e econômicas, era muito mais intenso do que se imagina. Para ilustrar este fato, será feita uma análise da obra de Cosme Indicopleustes, viajante alexandrino que, no Séc. VI, durante o reinado de Justiniano, escreve a "Topografia Cristã", obra que ao traçar uma ampla descrição da expansão geográfica da fé cristã, principalmente nas regiões orientais, representa uma tentativa de inserção desta parcela territorial no projeto político do imperador bizantino, ou seja, no próprio conceito de civilização deste contexto.

PALAVRAS-CHAVE: Civilização; Cosme Indicopleustes; Justiniano; Império Bizantino.

ABSTRACT: The studies of the contacts between Orient and Occident are normally restrained by the connections that took place after the beginning of the period called Medieval Age. Nevertheless, it is a normal conclusion to admit that both sides already "knew each other" at earlier periods and that the cultural, economical and social exchanges were more intense than we could imagine. To illustrate this fact, will be made an analysis of Kosmas Indicopleustes' work, an alexandrine traveler that, at the $6^{\text {th }}$ Century, during the reign of Justinian, wrote the "Christian Topography", a book that describes the expansion of the Christian faith in the orient regions and by doing so, represents an attempt of insertion of these territories in the political project of the emperor, or better, in the context's concept of civilization.

KEY-WORDS: Civilization; Kosmas Indicopleustes; Justinian; Byzantine Empire.

${ }^{1}$ Mestrando do programa de Pós-graduação em História da Universidade Federal do Paraná. 
Civilização, conceitualmente, é algo recorrentemente analisado pelas mais diversas camadas historiográficas. No entanto, é sempre um estudo que necessita especial atenção, pois todo e qualquer conceito é extremamente vinculado ao contexto que o abrange e inúmeras interpretações podem ser atribuídas ao mesmo termo em diferentes espaços de tempo ou mesmo em distintas localidades contemporâneas.

$\mathrm{Na}$ historiografia ocidental, os grandes precursores do uso desta idealização acerca do termo "civilização" foram os gregos. Tanto para eles, como para os primeiros romanos, esta teria um significado quase que étnico/lingüístico. Mas após o advento do cristianismo como religião oficial do império romano, a noção de civitas passou a ser, predominantemente, religiosa ${ }^{2}$. Entretanto, analisar as mudanças deste conceito através dos tempos e das organizações políticas daria, por si só, conteúdo para outra pesquisa e, portanto, excede este trabalho. A pesquisa aqui proposta busca identificar este conceito na obra de Cosme Indicopleustes, viajante alexandrino que, durante meados do século VI, parece indicar uma via alternativa desta noção tão cara aos poderes políticos da época e, mesmo se referindo aos lugares e comunidades que em uma primeira análise parecem divergir das políticas oficiais, com uma visão mais aprofundada mostra-se em total sintonia com os acontecimentos do grande centro político, econômico e religioso de sua época, a cidade que atraía para si todos os olhares, Constantinopla.

Constantinopla (atual Istambul) ou Bizâncio - como foi primeiramente denominada - foi fundada em 657 a.C., por imigrantes gregos de Megara. $\mathrm{O}$ nome é referente à divindade "Byzas", mítico monarca e fundador da cidade ${ }^{3}$. Com uma posição

\footnotetext{
${ }^{2}$ FRIGHETTO, Renan. Política e Poder na Antiguidade Tardia: uma abordagem possível. História Revista, Goiânia, v.11, n.1, p. 162.

${ }^{3}$ RIVEROS, J. M. \& HERRERA CAJAS, H. El Império Bizantino: introducción histórica y selección de documentos. Nea Hellás, Serie Byzantini Historia I. Universitad de Chile: Facultad de Filosofía y Humanidades, 1998, p. 15.
} 
geográfica extremamente privilegiada, sempre foi de vital importância para as unidades políticas que integrava.

O Império Bizantino, como instituição política própria, conta com datas extremamente precisas ${ }^{4}$, fundação em 11 de Maio de $330^{5}$ e término em 29 de Maio de $1453^{6}$. Primeiramente imaginado como porção oriental do Império Romano, as diferenças entre estas duas partes se tornavam cada vez mais evidentes. Enquanto o ocidente enfrentava graves crises políticas e econômicas, a porção oriental fundamentada em pilares como uma cultura própria, que abrangia o helenismo oriental e as formas administrativas da Roma ocidental; a língua grega; e a ortodoxia religiosa - se fortalecia.

A separação política efetiva foi realizada pelo imperador Teodósio I que ao morrer, em 395, dividiu o território entre seus herdeiros, Arcádio e Honório, levando em consideração as enormes diferenças entre as tradições culturais gregas e latinas. Enquanto o ocidente, ao cair em mãos bárbaras, se tornava mais ruralizado, Constantinopla mantinha o status de grande centro urbano ${ }^{7}$, promovendo, assim, uma movimentação imensa de pessoas e culturas em seu território. A ostentação, tão presente na cultura bizantina, é reflexo direto da imagem de superioridade que esta situação os levava a possuir. Demonstrações públicas de riqueza e de fúria descontrolada da massa eram, até certo ponto, normais ${ }^{8}$ na experiência social desta comunidade. Outro aspecto marcante da sociedade bizantina é a sacralidade do poder imperial, sendo a idéia de submissão a um poder superior, mesmo que inapto, associada à ordem natural das coisas ${ }^{9}$.

\footnotetext{
${ }^{4}$ Ibidem, p. 16.
}

5 Com o intuito de resolver problemas logísticos da distância entre a capital imperial e as principais campanhas militares da época, o imperador Constantino I reconstrói a cidade de Bizâncio, a renomeia Constantinopla, a torna a nova capital - a Nova Roma - e a dota de todo um aparato institucional para tal.

${ }^{6}$ Tomada da cidade de Constantinopla pelos turcos otomanos.

${ }^{7}$ CAVALLO, G. O Homem Bizantino. Lisboa: Presenta, 1998, p. 189.

${ }^{8}$ Ibidem, p. 18.

${ }^{9}$ Ibidem, p. 19. 
Cosme Indicopleustes escreveu a Topografia Cristã durante o reinado de Justiniano (527-565), personagem considerado por muitos como o último imperador do Império Romano do Oriente e o primeiro do Império Bizantino ${ }^{10}$. Este período de transição transpareceu em seus atos políticos. Foi com Justiniano que aconteceu a última tentativa de uma política de reunificação dos antigos territórios do Império Romano, além de representar a primeira vez que esta iniciativa partia do lado oriental do território. A "Renovatio Imperium" é um audacioso projeto de reconquista dos territórios ocidentais (como a Península Itálica e o Norte da África) e de expansão aos territórios orientais, representados imediatamente pelos maiores rivais dos bizantinos, os Persas da dinastia Sassânida.

Nenhum destes objetivos foi alcançado, as vitórias ocidentais se tornaram apenas temporárias e o confronto contra os Persas foi demasiadamente equilibrado para que fosse apontado qualquer resultado definitivo. A importância do extremo oriente nas pretensões, tanto do Império Bizantino, quanto da Pérsia, passava diretamente por esta questão, pois muito mais que simples parceiros comerciais de especiarias, uma aliança com o poderoso império da Ásia Central, o Império Chinês, muito além de resultar no controle efetivo das mais importantes rotas comerciais entre estes dois extremos, poderia significar, finalmente, a vitória que ambos os lados tanto almejavam ${ }^{11}$.

Justiniano foi, também, o imperador que renovou inúmeros aspectos administrativos do império. Sob o lema de "um rei, uma lei, uma fé" tentou unificar a cristandade e compilou uma série de leis que formariam o chamado "Código de Justiniano". No segundo aspecto obteve relativo êxito, seu codex jurídico ajudou a criar uma burocracia interna regularizada indispensável para que a extensão territorial fosse, ao menos e em grande parte, mantida. No primeiro aspecto, no entanto, fracassou como qualquer tentativa anterior.

\footnotetext{
${ }^{10}$ RIVEROS, J. M. \& HERRERA CAJAS, H. El Império Bizantino... p. 17.

${ }^{11}$ BROWN, Peter. El Primer Milenio de la Cristandad Occidental. Barcelona: Crítica, s/d, p. 156.
} 
Apesar de ser um período anterior ao grande cisma do oriente ${ }^{12}$ a unidade cristã já não apresentava meios de existir devido, em grande parte, as chamadas "seitas cristológicas", sendo as três principais representantes desta categoria o Arianismo, o Monofisismo e o Nestorianismo. $\mathrm{O}$ arianismo seria rechaçado e considerado heresia já no primeiro concílio ecumênico universal, o primeiro concílio de Nicéia, que ocorreu em 325, durante o reinado de Constantino I. As outras duas citadas são as que se encontram mais fortemente presentes no período que o trabalho abrange. $\mathrm{O}$ nestorianismo e o monofisismo são doutrinas criadas, ambas, no século $\mathrm{V}$ que, além de entrar em conflito com o credo niceno oficial, se contrapõem entre elas.

O nestorianismo tem seu advento com um monge alexandrino, que chega ao bispado em Constantinopla, chamado Nestório, segundo o qual há em Jesus Cristo duas pessoas distintas, uma humana e outra divina, completas de tal forma que constituem dois entes independentes. Esta doutrina seria condenada como heresia no Concílio de Éfeso, terceiro concílio ecumênico universal, que ocorreu no ano de 431.

O monofisismo (do grego $\mu$ ovo $=$ único) foi elaborado por Eutiques em reação ao nestorianismo e admitia em Jesus Cristo uma só natureza, a divina. Foi considerado heresia no Concílio de Calcedônia, quarto concílio ecumênico universal, no ano de 451 .

Contudo, mesmo com as condenações impostas, estas doutrinas heréticas ganhariam força ${ }^{13} \mathrm{em}$ diversas regiões, especialmente nas porções mais orientais do território, tanto dentro como fora das fronteiras imperiais, afinal esta foi a rota de fuga dos seguidores das mesmas ao serem considerados hereges pelos

\footnotetext{
${ }^{12}$ Ano de 1054, quando acontece a divisão formal da unidade cristã em Igreja Católica e Igreja Ortodoxa. Até então, mesmo com as já pujantes diferenças entre os credos, quando se cita a "religião oficial", ambas estão incluídas.

${ }^{13}$ Exemplo disso é que ainda em 533, no segundo Concílio de Constantinopla (quinto ecumênico universal), são discutidos e condenados os textos nestorianos de Teodoro de Mompsuesta; de Teodoreto de Ciro; e de Ibas, também chamado como o Cisma dos Três Capítulos.
} 
domínios centrais e, sistematicamente, impedidos de permanecer nas terras da cristandade.

Outra grande questão, fortemente debatida neste período inicial da oficialidade da fé cristã e presente diretamente na obra aqui referenciada, era a divergência na análise do texto bíblico, representada por duas escolas fundadas nas outras cidades que, junto com Constantinopla, talvez representassem os grandes ápices intelectuais desta época.

A primeira surge na cidade de Alexandria, seus seguidores, influenciados por dois filósofos gregos - Heráclito e Platão -, acreditavam que a verdade se encontrava alegoricamente oculta além da letra e da realidade visível ${ }^{14}$. Um dos primeiros a utilizar esta metodologia para o texto bíblico foi um judeu alexandrino chamado Filo, que ao interpretar o antigo testamento aplicava as idéias de Platão através de um método extremamente alegórico. Quando o evangelho alcançou a cidade e muitos se cristianizaram, os mesmos métodos continuaram a ser aplicados neste novo contexto e, com o surgimento da Escola Catequética de Alexandria, estas práticas se difundiram cada vez mais, tendo como outro grande representante neste período inicial, Origines (185-253). Este iria influenciar nomes importantes do pensamento teológico, como Eusébio de Cesárea, Cirilo de Alexandria e Dionísio o Grande.

A reação a esta corrente nasceu em Antioquia, com Luciano de Samosata (240-312), que fundou nesta cidade uma escola de interpretação bíblica conscientemente contrária ao método alegórico da escola de Alexandria. A metodologia difundida por Luciano pregava uma abordagem tão literal do texto bíblico que chegou a ser chamada, em períodos posteriores, de "gramático-histórica"15. Esta escola influenciou nomes como Teodoro de Mompsuesta, João

14 LOPES, Augustus Nicodemus. História da Interpretação Cristã da Bíblia. Disponível em http://www.monergismo.com/textos/hermeneuticas/he_augu1.pdf, p. 2 . Último acesso em $04 / 08 / 08$.

${ }^{15}$ Ibidem. pg. 5. 
Crisóstomo, Nestório (que baseou sua teoria sobre as naturezas de Cristo neste método), entre outros.

Sobre o autor, Cosme Indicopleustes, pouco se sabe. Na própria obra, no livro II, existem algumas menções a dados biográficos. Normalmente ele apenas se descreve como um "cristão". Este termo deve ter sido escolhido exatamente para se contrapor aos pagãos ou mesmo aos "falsos cristãos", ou seja, todos aqueles que aderem às crenças que ele tão veemente critica ao longo de toda a sua obra. É importante lembrar, também, que ele vive no mesmo período em que (depois de ver sua tentativa de conciliação inicial frustrada pelas condenações das doutrinas que ele primeiramente tentou integrar na unidade imperial) Justiniano empregou uma "cruzada anti-herética". Como Cosme era, muito provavelmente, nestoriano, permanecer anônimo era de vital importância não somente para que os leitores confiassem na ortodoxia religiosa por ele exaltada, mas também para que sua obra não fosse condenada, como havia acontecido, por exemplo, em 533, com os escritos nestorianos chamados de "Três Capitulos".

Cosme, possivelmente, nasceu em Alexandria e, por causa de sua crença, deve ter entrado em conflito com a maioria monofisita local. Embora o fato de que não possuía nenhum tipo de educação formal seja citado pelo próprio autor e refletido no seu estilo de escrita, o conhecimento de alguma bibliografia da época transparece visivelmente em seu texto. A própria escolha do titulo da obra reflete certa preocupação neste aspecto. Ao denominá-la "Topografia" (do grego topos $=$ estilo e graphia $=$ escrita) parece indicar alguns autores que lidos por ele, podem ter influenciado a sua forma de escrita. Os melhores exemplos são Heródoto (485?-420 a.C.) historiador grego e considerado como o pai da história, autor das "Historias", onde narra as Guerras contra os Persas; Plínio (23-79), naturalista romano, autor da "Naturalis Historia", um compêndio de ciências antigas distribuído em trinta e sete volumes; e Estrabão (6324 a.C.), historiador, geógrafo e filósofo grego, autor da obra "Geographia", na qual, em dezessete livros, descreve sobre locais e 
povos de todo o mundo que lhe era conhecido à época. Estes três são, inclusive, efetivamente citados por Cosme em mais de uma oportunidade.

A Bíblia, por motivos óbvios, é outra das fontes de conhecimento mais utilizada. Também se referencia muito em Patrício, igualmente conhecido como "Mar-Aba", katholikos ${ }^{16}$ persa entre 540 e 552 e, muito provavelmente, um dos instrutores de Cosme. Seu conhecimento prático também permeia toda obra, por isso se torna quase unanimidade considerar que exercia o ofício de viajante constantemente. Nas descrições de suas viagens, cita destinos como o Reino de Axum (atualmente a Etiópia), o Ceilão (atual Sri Lanka) - lugares estes que muito provavelmente tenha efetivamente conhecido - e a Índia - local do qual deve apenas ter ouvido falar.

Os viajantes cristãos eram, quase sempre, divididos em dois grandes grupos, os comerciantes, que na maioria das vezes realizavam viagens periódicas, contudo rápidas, com o intuito bem definido de lucrar no destino almejado; e os religiosos, normalmente ligados a alguma ordem monástica. Os primeiros, pouco produziram, seus relatos quase sempre se resumiam a constatações econômicas e cambiais. Os segundos eram missionários - franciscanos, dominicanos, nestorianos, entre outros - que visualizavam no Oriente uma região ainda carente de uma religião institucionalizada e, com isso, com chances de conversão aparentemente bastante favoráveis ${ }^{17}$. Porém, como essas empreitadas demandavam uma longa preparação e recursos extremamente altos, essas duas "classificações" não eram necessariamente excludentes. Normalmente, os sujeitos que se submetiam a estas viagens acumulavam diversas funções, por diversas vezes, também, os reinos cristãos aproveitavam os missionários como emissários de um poder

\footnotetext{
${ }^{16}$ Termo que se equivale, na jurisdição canônica, ao de Patriarca. Utilizado nas províncias cristãs da Mesopotâmia (Pérsia), Armênia e Geórgia.

${ }^{17}$ LABARGE, M. W. Viajeiros Medievales: los ricos y los insatisfechos. Madrid: Nerea, 1992.
} 
político que, igualmente, possuía fortes intenções políticas e econômicas direcionadas ao Levante. Os monges representavam o labor e os reis, o capital que financiava as viagens. Parecia um "acordo" favorável às duas partes envolvidas. Cosme parece se identificar com os dois grupos, pois apesar de ser primordialmente um viajante com intuitos teológicos - ao menos foi o que tentou passar pela obra deixada - o seu ofício diário foi, muito provavelmente, o de importador de especiarias.

O livro denominado "Topografia Cristã" - ou pelo menos os cinco primeiros tomos, núcleo original da obra ${ }^{19}$ - foi compilado e escrito, provavelmente, entre os anos de 547 e $549^{20}$. As edições atuais provêm, inicialmente, de três manuscritos, o Vaticanus, do século IX, onde consta a cópia mais antiga do original, sem autoria identificada, incompleto - pois conta com apenas dez livros - e com o título "O Livro do Cristão"; o Sinaiticus e o Laurentianus, ambos do século XI, com os doze livros que conhecemos até os dias atuais, com uma menção de autoria a um "monge" denominado "Cosme" e já com o título "Topografia Cristã". Lendo a descrição de cada capítulo fornecida pelo próprio autor, fica claro que mesmo com o título que the foi dado, esta obra ultrapassa apenas questões geográficas ou teológicas inerentes.

A obra é uma defesa dos princípios cristãos, debatendo as principais questões teológicas da época sempre em favor das teorias fundamentadas pelo conhecimento religioso, sendo, exatamente por isso, permeada por inúmeros fatores escatológicos e mitológicos. Mesmo que este aspecto da obra possa representar uma maior

\footnotetext{
${ }^{18}$ Nem sempre formal e muitas vezes subliminar.

19 ELVIRA, Miguel Angel. Experiencia y Teoria en Cosmas Indicopleustes. Disponível em $<$ http://interclassica.um.es/investigacion/hemeroteca/erytheia/numero_6_2_1985/e xperiencia_y_teoria_de_cosmas_indicopleustes $>$, p. 257. Último acesso em 06/08/08.

${ }^{20}$ RIVEROS, J. M. El Mundo como Morada: orden y propósito. Byzantion Nea Hellás, n.25. Universitad de Chile: Facultad de Filosofía y Humanidades, 2006, p. 139.
} 
dificuldade na análise da mesma, consiste em importante fator de inserção dos personagens em seu próprio contexto histórico, além de demonstrar uma forte tendência do autor junto à escola de Antioquia, representada pela busca constante de apenas interpretar os dados descritos na Bíblia literalmente, tratando a "palavra inequívoca de Deus" como a única e inquestionável fonte de ciência ${ }^{21}$.

Isto gera uma contradição que permeia toda a obra. Cosme é um paradigma inevitável entre os pensamentos científico e religioso. Utiliza-se de fatos, dados matemáticos e inúmeros outros artifícios quando estes o favorecem, mas sempre manipula os resultados para que nunca ultrapassem suas pré-concepções retiradas diretamente das Sagradas Escrituras. Para cada questionamento de seus opositores aos quais seus métodos científicos não resolvam, como por exemplo, certas movimentações de corpos celestes, a resposta é sempre a mesma "Este fato se deve unicamente a vontade de Deus". Isso deflagra outra característica muito criticada da obra, a falta de conhecimento das teorias as quais o autor tenta refutar, pois para ele, o simples fato de uma teoria não ter como base o texto dos Escritos Sagrados cristãos, já seria o suficiente para decretar sua falibilidade.

Essa defesa incessante e literal de certos aspectos descritos na Bíblia - representados, sobretudo, pela refutação da esfera terrestre ${ }^{22}$ - fazia com que a grande parte do ciclo intelectual da época o tratasse com pouquíssima seriedade. Dentre seus principais críticos podemos citar Philoponus (490-570), filósofo cristão grego, contemporâneo de Cosme e defensor da teoria da esfera terrestre, a qual divulgava na sua "Escola Geográfica"; e Fócio (820-891),

${ }^{21}$ ELVIRA, Miguel Angel. Experiencia y Teoria en Cosmas Indicopleustes..., p. 261.

${ }^{22}$ Apesar de ser normal na historiografia ocidental achar que a idéia da esfera terrestre é um fato relativamente recente, este conceito já existe desde a Grécia clássica. Em suma, os poucos autores ocidentais do mundo antigo ou medieval que comprovadamente combateram a esfericidade da Terra foram exceção, eles eram geralmente ignorados ou tratados com pouca seriedade nos círculos intelectuais de sua época. Para mais detalhes: RUSSEL, Jeffrey Burton. Inventando a Terra Plana. Ed. Unisa, 1999. 
patriarca de Constantinopla, e um dos primeiros leitores de Cosme a comentar seu texto, o qual critica enormemente pela tendência de interpretação literal do texto bíblico.

Por isso, a preservação da obra de Cosme muito se deve a inclusão, nas versões mais atuais, do livro XI, chamado pelo próprio autor de Desenhos e descrições dos animais das Índias, igualmente das árvores da Ilha de Taprobana. Este capítulo específico provavelmente deveria estar incluso em um tratado maior sobre geografia, mas como apenas uma pequena parte foi preservada, foi devidamente compilada, como um livro adicional, na obra maior do autor $^{23}$. Seus desenhos e descrições de animais e peças observados são tão detalhados que mesmo sem ter consciência, Cosme foi um dos precursores da ciência arqueológica ${ }^{24}$. Este foi, por muito tempo, o aspecto da obra mais apreciado, senão o único, pelos seus leitores. Exemplo disso é a declaração de Montfaucon, editor da primeira obra completa de Cosme, em 1706, de que o Livro XI é mais importante do que todo o restante da obra.

É somente com a análise de Wanda Wolska-Conus (responsável pela edição mais autorizada da obra de Cosme até os dias de hoje), a partir da década de 60 do século XX, que foi feita uma análise da obra sem os pré-conceitos pejorativos que as marcavam até então. Este resgate proporcionou outras abordagens possíveis, como as realizadas nos artigos de José Marín Riveros " $E l$ Mundo como Morada"25, o qual se dedica à análise de duas obras histórico/geográficas - Expositius Totius Mundi et Gentium, de autoria anônima; e a própria Topografia Cristã, de Cosme Indicopleustes - demonstrando que, mesmo permeadas de aspectos mitológicos, elas eram reflexo claro de como aqueles personagens enxergavam o contexto ao qual estavam inseridos; e o de Miguel

\footnotetext{
${ }^{23}$ ELVIRA, Miguel Angel. Experiencia y Teoria en Cosmas Indicopleustes..., p. 258.

${ }^{24}$ PACE B. Introduzione allo studio dell'archeologia. Ed. Mondadori, 1947, p. 30. ${ }^{25}$ RIVEROS, J. M. El Mundo como Morada: orden y propósito. Byzantion Nea Hellás, n. 25. Universitad de Chile: Facultad de Filosofía y Humanidades, 2006.
} 
Angel Elvira, intitulado Experiencia y Teoria en Cosmas Indicopleustes ${ }^{26}$ no qual o autor faz um histórico das análises da obra de Cosme; para citar alguns exemplos.

Todavia, existe ainda um aspecto da obra de Cosme Indicopleustes muito pouco trabalhado, bastante implícito, que parece transcender todas as querelas políticas e religiosas discutidas anteriormente e que possui um objetivo exatamente contrário, o de agregar.

Quando se analisa o fato de que ele escreve, ao menos em um primeiro momento, no mesmo período que o Imperador Justiniano demonstra certa tendência de aproximação com as doutrinas cristãs alternativas ao credo Niceno e que esta se insere no projeto de expansão territorial do império, nota-se que a obra se inclui perfeitamente neste contexto, pois não somente promoveu um levantamento das comunidades cristãs dentro e fora do império, mas o fez exatamente nas regiões que Justiniano pretendia ou reconquistar ou expandir seu domínio.

Deste modo, a pergunta principal a ser feita é, teria Cosme Indicopleustes direcionado sua obra ao Imperador? E se assim o fez, teria tentado propor a ele que o caminho mais rápido para esta expansão seria o de unificar a fé cristã sob sua tutela, pois esta já estava difundida nos alicerces dos territórios pretendidos? Apesar de ficar claro que a iniciativa parte muito mais do viajante para o imperador do que o contrário, pois Justiniano dificilmente teria encomendado a obra diretamente a Cosme, quando se analisa o contexto juntamente com algumas passagens da obra, as perguntas acima parecem fazer muito sentido. E o conceito primordial a ser analisado nesta questão é o de "civilização".

Como a sacralidade do poder imperial é um dos pilares fundamentais da vida política bizantina, a religião se tornava um dos caminhos, e talvez o mais direto deles, para que uma concepção de civilização alcançasse as partes mais remotas, pois mesmo se estas constituíssem comunidades ilhadas em territórios de dominação

${ }^{26}$ ELVIRA, Miguel Angel. Experiencia y Teoria en Cosmas Indicopleustes... 
distinta, elas sempre tenderiam a se identificar mais com as outras diversas populações cristãs, próximas ou distantes, do que com as imediações territoriais que as circulavam. Nota-se que Cosme incluía seus anseios dentro de todo um imaginário inerente a construção da imagem do poder imperial ${ }^{27}$, Imperator Defensor Christianitas, onde há um cristão, há a civilização e é dever do imperador protegê-lo.

Não é coincidência, também, que um dos aspectos principais da obra seja a discussão dos "lugares do mundo" e sua disposição. Ao fazer isso com o intuito de provar que as Sagradas Escrituras estavam certas, o autor pôde discorrer sobre as comunidades cristãs que habitavam esses lugares. Direcionar esta análise no lado e ao lado oriental do império, onde as comunidades são, em sua maioria, monofisitas ou nestorianas, em suma, consideradas heréticas pela Instituição Central da Igreja, tornava-se quase como uma proposta de que esta expansão ao Oriente só seria possível se a fé cristã fosse realmente unificada sob a proteção do imperador.

Juntamente com isso, outro conceito importante a ser analisado é a idéia de oikumene, ou seja, a noção de um mundo civilizado. Mas Cosme não inova neste sentido, textos que consideram o império romano como um império universal que abrigaria toda a raça humana e que estenderia sua soberania e hegemonia por todo o mundo (orbis terrarum) aparecem desde a época de Augusto $^{28}$, no século I a.C. Mas ainda se faz necessário que se explicite que este conceito não pode ser aplicado como o seria nos dias de hoje. Esta confusão entre oikumene e a Terra em sua totalidade, notada claramente em Cosme, não é de forma nenhuma apenas um desejo de que o império por ele defendido, através da fé por ele proclamada, atingisse os quatro cantos do planeta. Claro que

\footnotetext{
${ }^{27}$ CREMADES, Fernando Checa. Imágenes y Lugares: el sitio del retrato del rey. In: Quintas Jornadas de Estudios Históricos organizadas por el Departamento de Historia Medieval, Moderna y Contemporánea de la Universidad de Salamanca, 1995, p. 60.

28 VEGA. M. J. Hidalgo de la. Algunas Reflexiones sobre los limites del olkoumene em el Império Romano. Gérion. 2005. 23. n. 1, p. 274.
} 
o era também, mas para ele o Império Cristão sempre seria universal simplesmente por considerar os que estavam alheios a este fora da noção de civilidade e, assim, exclusos de qualquer classificação até que se civilizassem, ou seja, se cristianizassem.

Apesar de parecer uma obra que não suporte discussões, várias questões foram levantadas e as respostas só serão dadas quando as análises da obra de Cosme se desprenderem da característica mais criticada no próprio autor, privilegiar apenas as características literais do texto. A própria insistência dele em defender concepções tão ultrapassadas em sua própria época faz parte de importante dado a ser analisado para a compreensão do autor. O historiador italiano Arnaldo Momigliano, grande expoente quando se analisam as permanências culturais nas sociedades, ao discorrer sobre a história eclesiástica, diz "Igreja que rompe conscientemente com seus princípios e suas instituições é inconcebivel $^{, 29}$. Cosme, como sempre, aplicou isso no sentido literal.

\section{BIBLIOGRAFIA}

ÁlvaREZ, S. M. C. Relaciones entre el Imperio Romano y los Reinos del Lejano Oriente: verificación del intercambio a través de hallazgos de monedas romanas en la ruta de difusión del budismo. In: Semanas de Estúdios Romanos. vol. XI. Chile: Universidad Catolica de Valparaiso, 2002, pp. 243-258.

ASENJO, S. S. Vias de Relacion entre Roma y China. In: Semanas de Estúdios Romanos. vol. VI. Chile: Universidad Catolica de Valparaiso, 1991, pp. 163-174.

BLOCH, Marc. Apologia da História ou O Oficio do Historiador. Trad. André Telles. Rio de Janeiro: Jorge Zahar, 2002.

BREHIER, L. Les Instituitions de L'Émpire Byzantine. Paris: Albin Michel, 1970.

${ }^{29}$ MOMIGLIANO, Arnaldo. As Raízes clássicas da Historiografia Moderna. Tr. Maria Beatriz Borba Florenzano. Bauru: EDUSC, 2004, p. 194. 
. La Civilization Byzantine. Paris: Albin Michel, 1970.

BROWN, Peter. El Primer Milenio de la Cristandad Occidental. Barcelona: Crítica, s/d.

CABRERA, E. \& SEGURA, C. Historia de la Edad Media Bizancio. El Islam. Madrid: Editorial Alambra, 1988.

CAVALLO, G. O Homem Bizantino. Lisboa: Presenta, 1998.

CREMADES, Fernando Checa. Imágenes y Lugares: el sitio del retrato del rey. In: Quintas Jornadas de Estudios Históricos organizadas por el Departamento de Historia Medieval, Moderna y Contemporánea de la Universidad de Salamanca, 1995.

COLES, P. Os Turcos na Europa. Lisboa: Verbo, s/d.

CONESA, Rita Marin. Cristianismo y Aculturación em la Política de Justiniano (según Procópio de Cesárea). Antiguedad y Cristianismo: monografías históricas sobre la antiguedad tardia VII (Eds. A. G. Blanco \& J. M. B. Martínez). Universidad de Murcia, 1990, pp. 541549.

COOK, R. M. Os Gregos na Jônia e no Oriente. Lisboa: Verbo, 1971.

CRIVAT-VASILE, Anca. Mirabilis Oriens: fuentes y transmisión. Revista de Filologia Románica, n.11-12. Madrid: Univ. Complutense, 1994-95.

CUTLER, A. \& SPIESER, J. M. Byzance Médiévale. Paris: Gallimard, 1996.

DOMINI, A. História do Cristianismo. São Paulo: Edições 70, 1980.

DURANT, W. Nossa Herança Oriental. 3. ed. Rio de Janeiro: Record, s/d.

ELVIRA, Miguel Angel. Experiencia y Teoria en Cosmas Indicopleustes.

Disp.

em

$<$ http://interclassica.um.es/investigacion/hemeroteca/erytheia/numero 6_2_1985/experiencia_y_teoria_de_cosmas_indicopleustes > Último acesso em 08/08/2008.

FAVROD, C. Os Árabes. Lisboa: Dom Quixote, 1977.

FERNÁNDEZ, R. G. La Obra Legislativa de Justiniano y la Cristianización del Cosmos. In: Antiguedad y Cristianismo: 
monografías históricas sobre la antiguedad tardia VII (Eds. A. G. Blanco \& J. M. B. Martínez). Universidad de Murcia, 1990, pp. 495518.

FRIGHETTO, Renan. Cultura e Poder na Antiguidade Tardia Ocidental. Curitiba: Ed. Juruá, 2000.

GHARIB, G. Os Ícones de Cristo. São Paulo: Paulus, 1997.

GIORDANI, M. C. História do Império Bizantino. Petrópolis: Vozes, 1997.

GRISONI, D. A Ásia Bárbara e a China Sábia. In: LE GOFF, J. et. al. A Nova História. Lisboa: Edições 70, 1977, pp. 103-108.

GUIMARÃES, M. L. \& FRIGHETTO, R. Instituições, Poderes e Jurisdições: I Seminário Argentina-Brasil-Chile de História Antiga e Medieval. Curitiba: Juruá, 2007.

INDICOPLEUSTES, Cosme. Topografia Cristiana. Trad. De J. W. McCrindle, Hakluyt Society, 1998. Londres, 1897.

Winstedt. The Christian Topografy of Cosmas Indicopleustes. Cambridge University Press, 1909.

INDICOPLEUSTES, Cosme. The Christian Topography. Disponível em <http://www.tertullian.org/fathers/\#Cosmas_Indicopleustes $>$ Acesso em 17 jul. 2007.

Edição bilíngüe parcial: Cosmas Indicopleustes. The Fourth Book of the Christian Topography. Disponível em $<$ http://ccat.sas.upenn.edu/awiesner/cosmas.html $>$ Acesso em 17 jul. 2007.

LABARGE, M. W. Viajeiros Medievales: los ricos y los insatisfechos. Madrid: Nerea, 1992.

LE GOFF, Jacques \& SCHMITT, Jean Claude. Dicionário Temático do Ocidente Medieval - v.1. Rio de Janeiro: Jorge Zahar Editor, 1989.

LEMERLE, P. História de Bizâncio. São Paulo: Martins fontes, 1991.

LOPES, Augustus Nicodemus. História da Interpretação Cristã da Bíblia. 
$<$ http://www.monergismo.com/textos/hermeneuticas/he_augu1.pdf $>$ Último acesso em 04/08/08.

LOZANO, A. Alejandro ante el cínico Diógenes: la confrontación del pensamiento y la ación. In: Alejandre Magno. Hombre y Mito (J. Alves \& J. M. Blazquez Eds.), Madrid, 2000, pp. 153-69.

MAIER, F. G. Bizancio. México/Madrid: Siglo XXI. C. História Universal, v.13, 1983.

MOMIGLIANO, Arnaldo. As Raizes clássicas da Historiografia Moderna. Tr. Maria Beatriz Borba Florenzano. Bauru: EDUSC, 2004.

PACE B. Introduzione allo studio dell'archeologia. Ed. Mondadori, 1947.

PROCOPIO. Historia Secreta. Trad. de N. Dottori, estudo preliminar e seleção de Virginia Erhart, Biblioteca Básica Universal. Buenos Aires: Centro Editor de América Latina, 1983.

1940.

. De Aedificiis. Trad. inglesa de H. B. Dewing. Londres,

RIVEROS, J. M. El Mundo como Morada: orden y propósito. Byzantion Nea Hellás, n. 25. Universitad de Chile: Facultad de Filosofía y Humanidades, 2006, pp. 129-156.

RIVEROS, J. M. \& HERRERA CAJAS, H. El Império Bizantino: introducción histórica y selección de documentos. Nea Hellás, Serie Byzantini Historia I. Universitad de Chile: Facultad de Filosofía y Humanidades, 1998.

RUNCIMAN, S. A Civilização Bizantina. Rio de Janeiro: Zahar Editores, 1981.

RUSSEL, Jeffrey Burton. Inventando a Terra Plana. Ed. Unisa, 1999.

SAID, E. Orientalismo. São Paulo: Cia. das Letras, 1990.

VEGA. M. J. Hidalgo de la. Algunas Reflexiones sobre los limites del olkoumene em el Império Romano. Gérion. 2005. 23. n. 1.

VRYONIS, S. Bizâncio e a Europa. Lisboa: Verbo, 1967.

WALTER, G. A Vida Cotidiana em Bizâncio. Lisboa: Ed. Livros do Brasil, s/d. 